\title{
Combination of EZH2 inhibitor and BET inhibitor for treatment of diffuse intrinsic pontine glioma
}

\author{
Yaqin Zhang ${ }^{1}$, Weijie Dong ${ }^{2}$, Junying Zhu ${ }^{3}$, Lizhu Wang ${ }^{1}$, Xinjian $\mathrm{Wu}^{2^{*}}$ and Hong Shan ${ }^{4^{*}}$
}

\begin{abstract}
Background: Diffuse intrinsic pontine glioma is an infiltrative, often high-grade glioma of the brainstem that is not amenable to surgical resection. The current treatment of DIPG by radiation therapy showed dramatically improvement of patient's condition, however, the tumor recurs rapidly. More and more studies are focused on the genetic and epigenetic drivers of DIPGs, which may provide more and more novel therapy target for DIPG. EZH2 has been proved to be a potential therapeutic target for H3K27M-mutant pediatric gliomas recently. Meanwhile, BET family protein is a hot target in many different types of cancers, including DIPG. In this study, we performed the treatment of both EZH2 and BET inhibitor for DIPG cells.

Results: The combination of these two inhibitors exhibited better inhibition of the tumor growth both in vitro and in vivo compared to use the inhibitor individually. This inhibition was performed by blocking the proliferation and promoting the cell apoptosis. Meanwhile, combination treatment of these two inhibitors would also affect the epigenetic markers which were abnormal in the tumors of the certain set of genes.
\end{abstract}

Conclusion: Thus we provided a novel therapy strategy for clinical treatment of DIPG.

Keywords: DIPG, EZH2 inhibitor, BET inhibitor, Epigenetics, Tumor therapy

\section{Background}

Diffuse intrinsic pontine glioma (DIPG), a tumor located in the middle of the brain stem, is a fatal malignant pediatric brain tumor, which is the leading cause of cancer-related mortality in children [1]. The 5-year survival rate of DIPG is $<1 \%$. The median overall survival of children diagnosed with DIPG is approximately 9 months and the 1- and 2-year survival rates are approximately $30 \%$ and less than $10 \%$, respectively [2]. So far, radiotherapy, which offers a significant but transient improvement, is the standard treatment of DIPG, while chemotherapy has not shown any benefit $[1,3]$. So more understanding

\footnotetext{
*Correspondence: wuxj514@sina.com; shanhong020@gmail.com ${ }^{2}$ Neurosurgery Department, The 1st Affiliated Hospital of Sun Yatsen University, No. 58 Zhongshan No. 2 Road, Guangzhou 510030, Guangdong Province, People's Republic of China

${ }^{4}$ Department of Interventional Medicine, The 5th Affiliated Hospital of Sun Yat-sen University, No. 52 Meihua Dong Road, Zhuhai 519000, Guangdong Province, People's Republic of China

Full list of author information is available at the end of the article
}

of the molecular mechanism of DIPG is required to find the new target and develop more specifically therapeutic approaches for DIPG.

Nearly $80 \%$ of DIPGs harbor histone H3 mutations, wherein lysine 27 is substituted with methionine (H3K27M) [4-8]. DIPGs expressing H3K27M mutant will reduce the global levels of H3K27me3 [9], which is mediated by PRC2 [10]. Polycomb repressive complexes (PRCs), including PRC1 and PRC2, mediate gene silencing by posttranslational modification of histones [11, 12]. The PRC2 complex takes responsibility for trimethylation of Lys 27 of histone H3 (H3K27me3), this modification is catalyzed by its enzymatic subunits EZH1 and EZH2 [13]. EZH2 is actively involved in many cellular processes such as cell cycle progression, cell proliferation, cell differentiation and apoptosis [14]. EZH2 mutations have been found to relate to multiple human cancers [15]. Recent study shows that EZH2 activity is required for the growth of mouse DIPG tumor cells in vitro [16]. 
The bromodomain and extraterminal (BET) family proteins, which playing a key role as epigenetic regulators, are responsible for the transcriptional activation by interaction with acetylated $[17,18]$ chromatin $[19,20]$. BET proteins regulate the expression of many important oncogenes, which involved in apoptosis and cell cycle arresting [21-23]. Therefore, small molecule inhibitors of BET proteins have been developed and proved to be active in both solid and hematologic malignancies, including brain tumors [24, 25]. JQ1, reported by Filippakopoulos et al. is a small molecule that competitively binds to bromodomains with high potency and specificity. Taylor et al. found that combination targeting MYCN and $\mathrm{NOTCH}$ by JQ1 and MRK003 inhibited DIPG growth and induced apoptosis, suggesting this may work as an effective therapeutic strategy in DIPG.

In this study, we performed the treatment of both EZH2 and BET inhibitor for DIPG cells in order to examine whether combination treatment would be better than the treatment of the inhibitor individually. This study was aim to find the new strategy of chemotherapy for the treatment of DIPG.

\section{Methods and materials}

\section{Cell lines and culture}

NSCs were isolated from the dorsal forebrain of mouse embryos at E12.5. After the embryos were isolated, the skin is removed, then the dorsal forebrains were dissected out and incubated in $0.25 \%$ trypsin-EDTA (GIBCO, Grand Island, NY, USA) at $37^{\circ} \mathrm{C}$ for $20 \mathrm{~min}$. The tissue was dissociated by pipette thoroughly, and then cultured in the poly-D-lysine (PDL, Sigma-Aldrich, St. Louis, MO, USA)- and laminin (Sigma-Aldrich, USA)-coated plates in neural stem cell medium. The neural stem cell medium contained 50\% DMEM-F12, 50\% neurobasal medium, $\mathrm{N} 2$ and B27 supplements, sodium pyruvate, glutamax, HEPES, $\beta$-mercaptoethanol, non-essential amino acids, bovine serum albumin, heparin, $100 \mathrm{U} / \mathrm{ml}$ penicillin, $100 \mu \mathrm{g} / \mathrm{ml}$ streptomycin, human recombinant epidermal and basic fibroblast growth factors. After 3 days culture, the cells were treated with $0.25 \%$ trypsin-EDTA and snap freezed by liquid nitrogen in NSC medium supplemented with $10 \%$ DMSO.

\section{Reagents}

DMEM-F12 was bought from GIBCO (USA). The charcoal-stripped fetal calf serum (FCS) was purchased from HyClone Laboratories (Inc., Logan, UT, USA). Antimouse Flag-tag, HA-tag, H3, H3K27me3 and GAPDH were bought from Sigma-Aldrich (Inc, USA). Cell counting kit-8 was bought from Dojindo Laboratories (Inc, Japan). The EZH2 inhibitor EPZ6438 and BET inhibitor JQ-1 were from Selleck Chemicals.

\section{Flow cytometry and apoptosis}

Cells with different treatments were washed twice in FACS medium phosphate buffered PBS containing 1\% FCS and $0.1 \% \mathrm{NaN}_{3}$. Then the cells were washed by AnnexinV binding buffer for 3 times. After centrifugation and discuss the supernatant, cells were incubated for $30 \mathrm{~min}$ at $4{ }^{\circ} \mathrm{C}$ with FITC-AnnexinV according to the standard procedure. PI was added before testing. Fluorescence was measured by using a FACSCalibur (Becton-Dickinson, San Diego, CA) and data were analyzed by using the Flowjo Software (Becton-Dickinson, San Diego, CA).

\section{Chromatin immunoprecipitation (ChIP)}

Around $5 \times 10^{7}$ cells were incubated with $37 \%$ Formaldehyde diluted to a $1 \%$ final concentration for crosslinking for $15 \mathrm{~min}$ at room temperature. $1 \mathrm{M}$ Glycine diluted to a final concentration of $125 \mathrm{mM}$ was added to stop the crosslink at room temperature for $5 \mathrm{~min}$. Cells were pelleted and resuspent in $5 \mathrm{ml}$ of Lysis Buffer $(10 \mu \mathrm{g} / \mathrm{ml}$ Leupeptin, $10 \mu \mathrm{g} / \mathrm{ml}$ Aprotinin, and $1 \mathrm{mM} \mathrm{PMSF}$ ) and aliquoted to the $1.5 \mathrm{~mL}$ eppendorf tubes $500 \mu \mathrm{l}$ each, then the samples were incubated on ice for $10 \mathrm{~min}$. Samples were sonicated by Bioruptor ${ }^{\mathrm{TM}}$ UCD-200 to generate $500 \mathrm{bp}-1 \mathrm{~kb}$ length DNAs. Then $500 \mu \mathrm{l}$ of each sample was centrifuged for $10 \mathrm{~min}$ at $12,000 \mathrm{~g}$. Supernatant was collected and diluted by adding $1 \mathrm{ml}$ of Dilution Buffer (containing the same amount of protease inhibitors as in Lysine Buffer) and add $5 \mu$ g of the antibody or normal IgG to the samples. Tubes were incubated at room temperature for $15 \mathrm{~min}$ and then secondary antibody was added into the tubes, after another incubation at room temperature for $15 \mathrm{~min}, 4$ times of washing were performed by Wash Buffers pre-chilled to 2 to $8{ }^{\circ} \mathrm{C}$. After the final wash and centrifugation, $120 \mu \mathrm{l}$ of deionized or distilled water was added to the system to resuspend the DNAs. 2-10 $\mu \mathrm{l}$ of the DNA sample was used in the q-PCR reactions.

\section{Soft-agar colony formation assay}

Cells with different treatments were harvested and pipetted well to become single-cell suspension in complete culture media in a concentration of $1 \times 10^{6} / \mathrm{ml}$. Then the cells were incubated at room temperature for using. $10 \%$ FBS DMEM was pre-warmed at $37{ }^{\circ} \mathrm{C}$ and $4 \%$ agar was melted by microwave and keep warm in $56^{\circ} \mathrm{C}$ water bath. $0.9 \mathrm{ml} 4 \%$ agar and $4.1 \mathrm{ml}$ pre-warmed of $10 \%$ FBS DMEM were mixed well and put into $60-\mathrm{mm}$ culture dish in the hood. After it became solid, $3 \times 10^{4}$ cells, $2.73 \mathrm{ml}$ pre-warmed 10\% FBS DMEM and $270 \mu \mathrm{l}$ of $4 \%$ pre-warmed agar were mixed together to form the top gel. After the gel became solid, the dish were incubated at $37^{\circ} \mathrm{C}$ for 3 weeks. Then the colonies were stained with $0.04 \%$ crystal violet- $2 \%$ ethanol in PBS. 


\section{Western blot analysis}

Cells $\left(1 \times 10^{7}\right)$ were lysed in a buffer containing $20 \mathrm{mM}$ Tris- $\mathrm{HCl}$ (pH 7.6), $250 \mathrm{mM} \mathrm{NaCl}, 0.5 \% \mathrm{NP}-40,3 \mathrm{mM}$ EDTA and $1.5 \mathrm{mM}$ EGTA with $10 \mu \mathrm{g} / \mathrm{ml}$ Aprotinin, $10 \mu \mathrm{g} / \mathrm{ml}$ leupeptin, $1 \mathrm{mM}$ DTT, $1 \mathrm{mM}$ PNPP and $0.1 \mathrm{mM}$ $\mathrm{Na}_{3} \mathrm{VO}_{4}$ as protease and phosphatase inhibitor. After centrifugation, cell lysates $(100 \mu \mathrm{g} /$ lane $)$ were subjected to $10 \%$ SDS-PAGE and transferred onto polyvinylidene difluoride membranes (Roche, Germany). The membranes were blocked for $1 \mathrm{~h}$ in TBST $(25 \mathrm{mM}$ Tris- $\mathrm{HCl}$, $\mathrm{pH} 7.6,125 \mathrm{mM} \mathrm{NaCl}, 0.1 \%$ Tween-20) containing 5\% nonfat dried milk, and then the membrane was incubated with antibodies against Flag-tag, HA-tag, H3K27me3, H3 or GAPDH was diluted in TBST containing $5 \%$ nonfat dried milk at $4{ }^{\circ} \mathrm{C}$ overnight. HRP conjugated goat antirabbit or anti-mouse antibodies were used as second antibodies. All the antibodies were from Sigma. Protein bands were detected by the Immobilon Western Chemiluminescent HRP Substrate (Millipore, Billerica, MA, USA) and images were taken by FluorChem FC2 System (Alpha Innotech Corporation, USA).

\section{The cell proliferation assay}

The cell proliferation was detected cell counting or by a Cell Counting Kit- 8 according to the manufacturer's instructions.

\section{Animals and surgical procedures}

Six-week-old female BALB/c mice were provided by the animal center in Sun Yat-sen University. All protocols, described below, were approved by the Animal Care and Use Committee of Sun Yat-sen University. $1 \times 10^{5}$ PDGFB/H3K27wt or PDGFB/H3K27M cells suspended in $1 \mu$ l Hank's balanced salt solution without $\mathrm{Ca}^{2+}$ and $\mathrm{Mg}^{2+}$ were injected slowly (over $1 \mathrm{~min}$ ) into the pontine tegmentum at 5-mm depth from the inner base of the skull. Inhibitors were injected by intraperitoneal (i.p.) injection with the amount as indicated in the figure legend 5 days after the tumor generation. Mice were monitored daily and recorded the survival rate.

\section{Statistical analysis}

Results were expressed as mean $\pm \mathrm{SD}$. $\mathrm{p}$ values were determined using two-tailed Student's $t$ test. $\mathrm{p}$ values were indicated in each figure.

\section{Results}

\section{H3K27M is sufficient to generate tumors}

As reported, H3K27M-mutant expression in DIPGs is associated with up-regulation of PDGF signaling [4, 5], so we expressed Flag-tagged K27M H3.3 mutant or Flag-tagged H3K27wt in mouse neural stem cells (NSCs) expressing HA-tagged-PDGFB. Figure 1a showed the
NSC cells expressed with both Flag-tagged H3K27M and HA-tagged-PDGFB exhibited a global reduction of H3K27me3. Consistent with other's reports [4, 9, 16, 26], these PDGFB/H3K27M NSCs had an improved ability of colony-forming compared to the PDGFB/H3K27wt cells (Fig. 1b). Meanwhile, the PDGFB/H3K27M NSCs grew faster than the PDGFB/H3K27wt cells, which made the PDGFB/H3K27M NSCs could generate the larger tumor when implanted to the pons of the mice (Fig. 1c). Then we used mice model to evaluate the tumor formation ability of the modified NSCs. The mice implanted the PDGFB/ H3K27M NSCs developed larger tumors than the wt cells (Fig. 2a), and PDGFB/H3K27M group had poor survival rate compare to the PDGFB/H3K27wt (Fig. 2b). These results were consistent with the recent research and indicated that H3K27M is sufficient to generate DIPG.

\section{Combination of EZH2 and BET inhibitors on the tumor cells proliferation and apoptosis}

Although H3K27M mutant tumor cells exhibited the global reduction in H3K27me3 levels (Fig. 1a), recent studies showed that several genes, especially several tumor-suppressor genes, retained or even showed increased H3K27me3 levels [27, 28]. Due to this point, EZH2 activity has been proved to be required for the growth of mouse DIPG cells in vitro and in vivo [16]. In the other hand, BRD2 and BRD4 proteins were found to co-occupy with H3K27M-K27ac, then logically, the BET inhibitor was also demonstrated could efficiently inhibit tumor progression [29]. Therefore, we thought these two inhibitor may both be potential for clinical trial, so we tested the effect of combination of these two inhibitors. The cell counting (Fig. 3a) and cell viability presented by cck-8 kit (Fig. 3b) indicated that both of EZH2 inhibitor (EPZ6438) and BET inhibitor (JQ-1) could reduce the proliferation of PDGFB/H3K27M NSCs. Interestingly, combination of these two inhibitors exhibited better reduction compare to only using one inhibitor (Fig. 3a, b). We got the similar results on the apoptosis assay by FITC-AnnexinV and PI staining. The PDGFB/H3K27M NSCs showed the very low basal apoptotic ratio (Fig. 4a). Treatment of EPZ6438 or JQ-1 remarkably promoted the apoptosis and the combination of these two inhibitors showed the further induction of apoptosis (Fig. 4a, b). Thus, we have demonstrated that EZH2 and BET proteins activity were required for the growth of PDGFB/ H3K27M NSCs, inhibition of these two group of proteins showed an impressive interfere in tumor progression.

\section{Combination of EZH2 and BET inhibitors epigenetically regulated several tumor-suppressors}

Several tumor-suppressors, including $\mathrm{p} 16^{\mathrm{INK} 4 \mathrm{~A}}$ and CDKN2A, have been reported to have the reduced 
$\mathbf{a}$
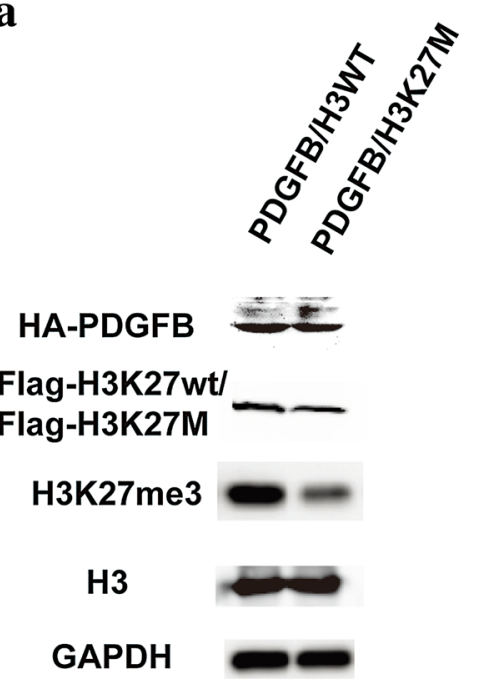

b

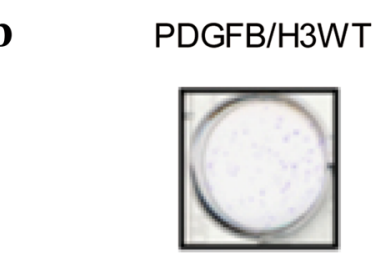

PDGFB/H3K27M

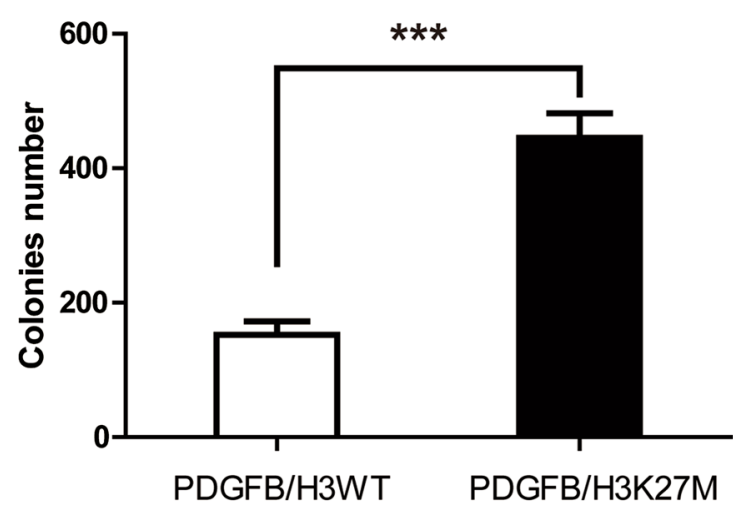

c

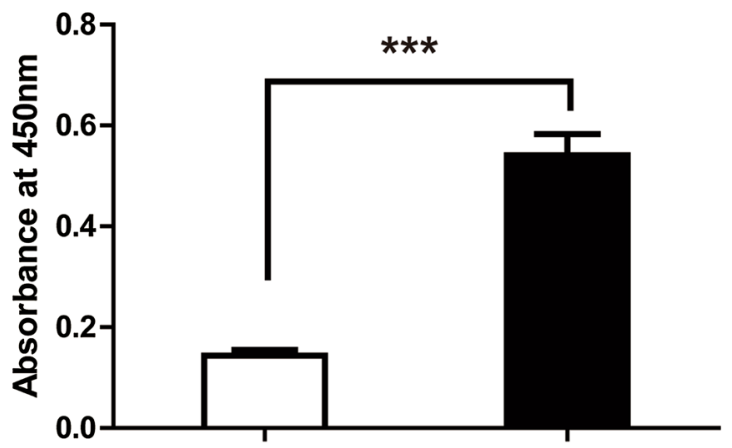

Fig. 1 H3K27M make the NSCs gain the tumor activity. a Western blot showing the expression level of Flag-tagged-H3K27M or Flag-taggedH3K27wt, HA-tagged-PDGFB, H3K27me3, H3 and GAPDH. b Soft agar colony assay of PDFGB/H3WT or PDGFB/H3K27M NSCs. Data were represented as mean $\pm S D, n=3$ independent experiments. ${ }^{* *} p<0.001$. c Cck-8 kit was used to evaluate the viability of PDFGB/H3WT or PDGFB/ H3K27M NSCs. Data were represented as mean $\pm S D, n=3$ independent experiments. ${ }^{* *} p<0.001$

expression due to the retain $\mathrm{H} 3 \mathrm{~K} 27 \mathrm{me} 3$ activity in H3K27M induced DIPG tumors [16]. So we were interested whether combination of EPZ6438 and JQ-1 would also work on these epigenetic markers. We used ChIP-qPCR to test the H3K27me3 levels on the $\mathrm{p} 16^{\mathrm{INK} 4 \mathrm{~A}}$ promoter. We could see the increased H3K27me3 on the p16 ${ }^{\mathrm{INK} 4 \mathrm{~A}}$ promoter and EPZ6438 or JQ-1 would dramatically reduce the $\mathrm{H} 3 \mathrm{~K} 27 \mathrm{me} 3$ level while both of them showed totally abolish of the H3K27me3 activity (Fig. 5a). Igf2bp2 is a typical gene that will lose H3K27me3 with the expression of H3K27M, ChIP-q-PCR result showed that there is no effect of the inhibitors on this type of genes (Fig. 5b). H3K27M is reported to correlate with
H3K27ac, however, this correlation is excluded by the PRC2 targets [29]. So we took the HOXA10 as an example to test the epigenetic changes in the PRC2 targets by the treatment of EPZ6438 and/or JQ-1. To our surprise, although the PRC2 targets also retained the H3K27me3 activity, neither of these two inhibitors would affect the H3K27me3 levels in the PDGFB/H3K27M NSCs (Fig. 5c). These results suggested that EPZ6438 and JQ-1 would change the epigenetic marks of the genes which been abnormally repressed in PDGFB/H3K27M NSCs, they would not affect the PRC2 targets to change their original repression pattern. Meanwhile, we detected the mRNA levels of these three different types of the genes, 


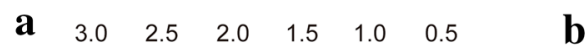

b
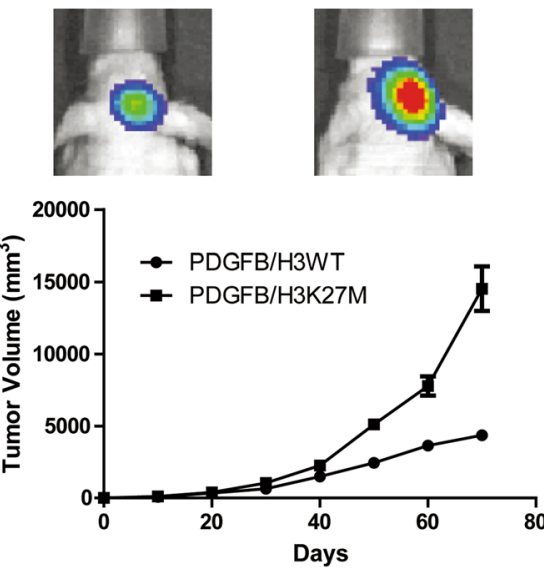

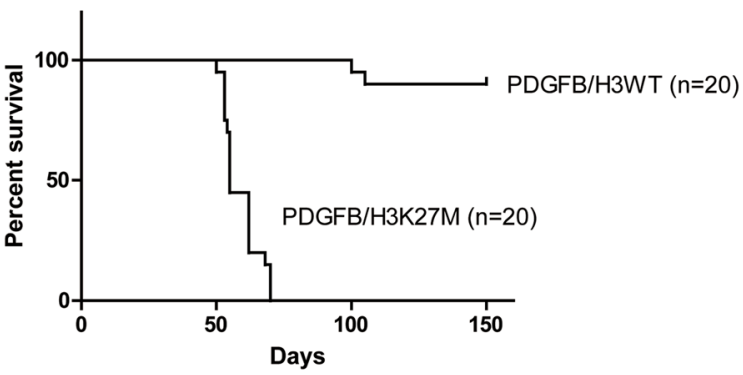

Fig. $2 \mathrm{H} 3$ K27M is sufficient to generate DIPG tumors. a Tumor generated by PDFGB/H3WT or PDGFB/H3K27M NSCs was measured in diameters and calculated to volume according to the time point. b Survival curve of the mice injected into the pons with PDFGB/H3WT or PDGFB/H3K27M NSCs $\left(1 \times 10^{5}\right)$. Each group contains 20 mice
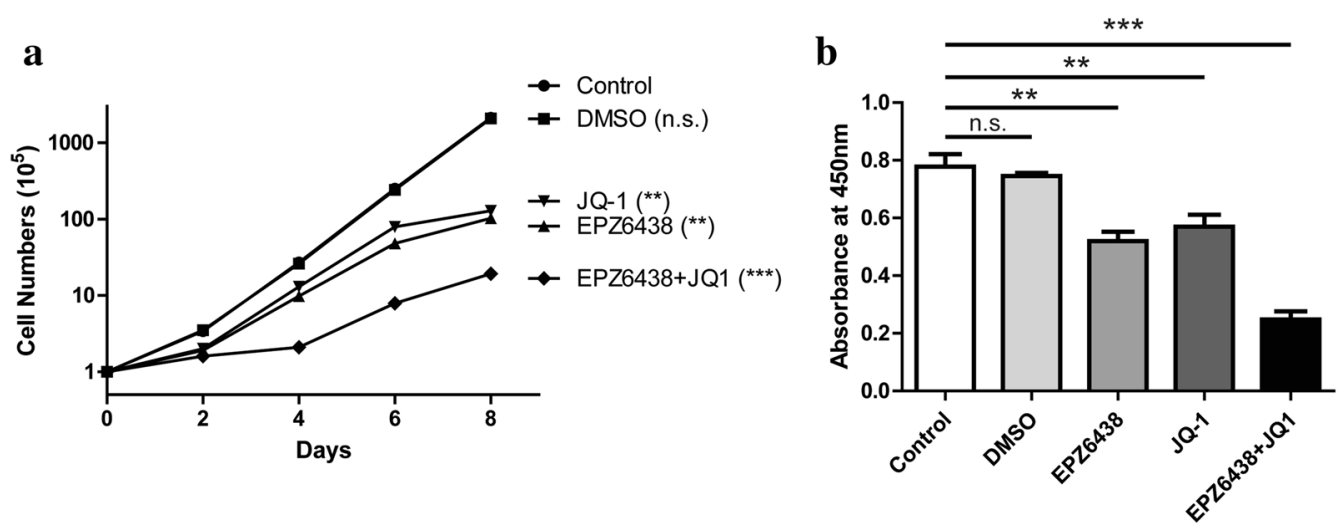

Fig. 3 Combination of EZH2 and BET inhibitors reduced the cell proliferation in DIPG cells. a Cell proliferation of different groups as indicated was determined by cell counting. The concentration of EPZ6438 was $3 \mu \mathrm{M}$ and JQ-1 was $300 \mathrm{nM}$, the following in vitro assay used the same amount of the inhibitors. ${ }^{* *} p<0.01$ and ${ }^{* * *} p<0.001$. b Cck-8 kit was used to evaluate the viability of each group of the cells as indicated. Data were represented as mean $\pm S D ; n=3$ independent experiments. ${ }^{* *} p<0.01$ and ${ }^{* * *} p<0.001$

the expression levels were consistent with the ChIP results for these three types of the genes (Fig. 6).

\section{Combination of EZH2 and BET inhibitors improved survival in mice model}

Finally, we tested the combination effect of EPZ6438 and JQ- 1 on the mice model. The mice were implanted the PDGFB/H3K27M NSCs in the pons and treated with EPZ6438 and/or JQ-1 by tail vein injection. Treatment of the inhibitors individually showed the improvement in survival and the combination of these two inhibitors showed a prolonged survival which still had half of the mice alive after 150 days (Fig. 7).

\section{Discussion}

DIPG is a highly aggressive pediatric brainstem tumor characterized by rapid and uniform patient demise. DIPGs usually grow quickly and affect important parts of the brain. The standard treatment for DIPG is radiation therapy, although it can dramatically improve patient's condition, it usually recur after 6-9 months and progress rapidly. To find the new target and develop more specifically therapeutic approaches for DIPG became important to this tumor.

Previous studies uncovered that nearly 78\% DIPG contained histone H3 gene mutations on lysine 27. Since human has dozens copies of Histones, H3K27M 


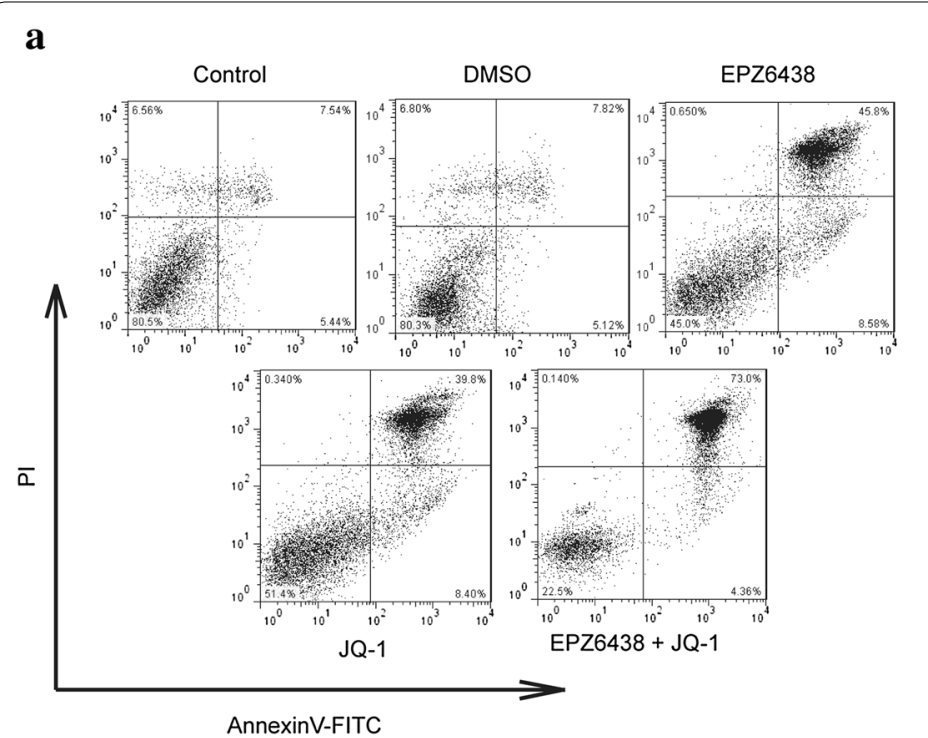

b

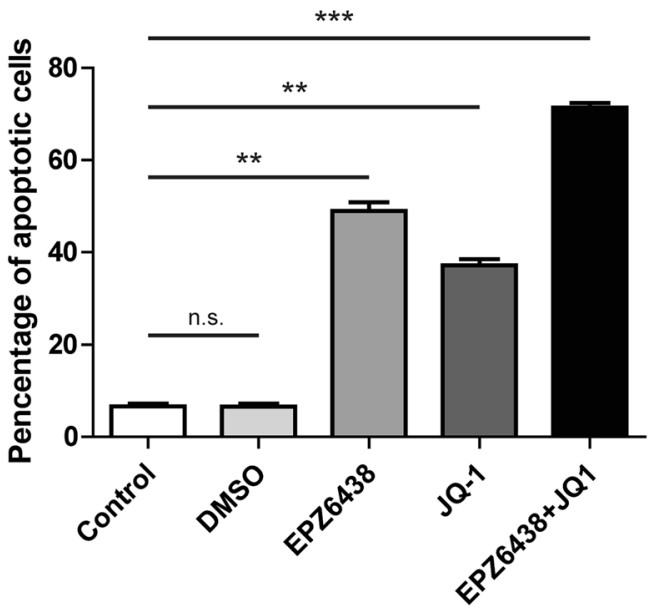

Fig. 4 Combination of EZH2 and BET inhibitors promoted the cell apoptosis in DIPG cells. a The apoptosis of the DIPG cells with different treatment as indicated was determined by using the Annexin-V-FITC \& PI Apoptosis Kit and assessed by flow cytometry. $n=3$ independent experiments and this panel presented one of these repeats. $\mathbf{b}$ Statistic of percentage of the apoptosis cells performed in $\mathbf{a}$. Data showed the Annexin-V and PI double positive cells. Data were represented as mean \pm SD; $n=3$ independent experiments. ${ }^{* *} p<0.01$ and ${ }^{* * *} p<0.001$

therefore constitutes a minor part (3.6-17.6\%) of total Histone 3, this minor part of H3K27 mutation would make the global reduction of H3K27me3 levels [9]. However, recent work by ChIP-seq analysis showed that, several sets of genes retain H3K27me3 in H3K27M-mutant DIPGs [16, 27-29]. This is quite interesting cause some of these genes are tumor suppressors and the retaining of the H3K27me3 makes them keep silencing when the tumor under progress, which may be the potential target for the clinical treatment. Due to this, EZH2, which is the core member in PRC2 complex, was found to be required for the DIPG growth and it inhibitor had the effect on the tumor transplanted to the mice model. Meanwhile, when the nucleosomes lose H3K27me3 because of H3K27M occupation, they usually acquire H3K27ac, which results in the formation of H3K27M-K27ac heterotypic nucleosomes [9]. Piunti et al. found that bromodomaincontaining protein 2 (BRD2) and BRD4 showed highly overlap with H3K27M-occupied sites [29]. This cooccupancy between bromodomain-containing protein and H3K27M-K27ac heterotypic nucleosomes indicates a potential role of BRD proteins in DIPG pathogenesis. Due to this, they used a well-known bromodomain and extra-terminal domain (BET) inhibitor, JQ-1, to treat the DIPG cells and animal model and demonstrated JQ-1 inhibited the tumor growth both in vitro and in vivo. Thus, BET inhibitors may also be a promising therapeutic strategy in DIPG.
Since DIPG is not a single gene disorder, develop more targets may be benefit in the clinical treatment. In this study, we test the combination effect of EZH2 inhibitor and BET inhibitor, in order to evaluate whether this combination is better for the treatment of DIPG. We generated H3K27M over-expressed mouse NSCs with the expression of $\mathrm{PDGFB}$, which is proved to be similar to the human DIPG. Then we treated the cells with EPZ6438 and/or JQ-1. Our results showed that each inhibitor had the effect on the proliferation and apoptosis of the PDGFB/H3K27M NSCs, interestingly, combination of these two inhibitors exhibited better effect on suppressing growth of the tumor cells. In order to provide the detail mechanism, we examined the epigenetic markers of different kind of genes. $\mathrm{p} 16^{\mathrm{INK} 4 \mathrm{~A}}$ is a tumor-suppressor protein which acts as a cell-cycle inhibitor. Expression level of p16 will be strongly induced by stress and oncogene activation. ChIP-q-PCR showed p16 would has an increased H3K27me3 activity when H3K27M was expressed, this induction of H3K27me3 levels could be dramatically inhibited by EPZ6438 or JQ-1. Combination of these two inhibitors showed the better inhibition of H3K27me3 activity, which can activate the gene expression of p16 and thus to suppress the tumors. Igf2bp2 is another type of genes, which would lost H3K27me3 activity in the presence of H3K27M. This is the most cases because H3K27me3 is globally reduced when H3K27M exists in the cells. Under this condition, EPZ6438 or JQ-1 would not affect the H3K27me3 levels, since it is already lost. 
$\mathbf{a}$

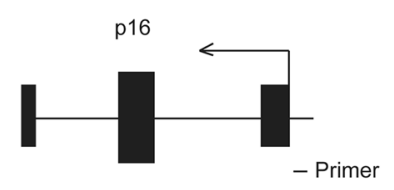

H3K27me3 ChIP
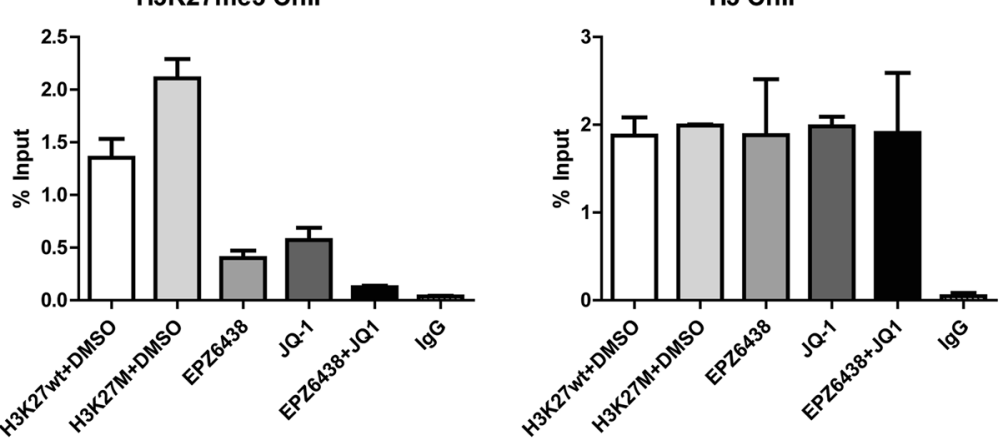

H3 ChIP
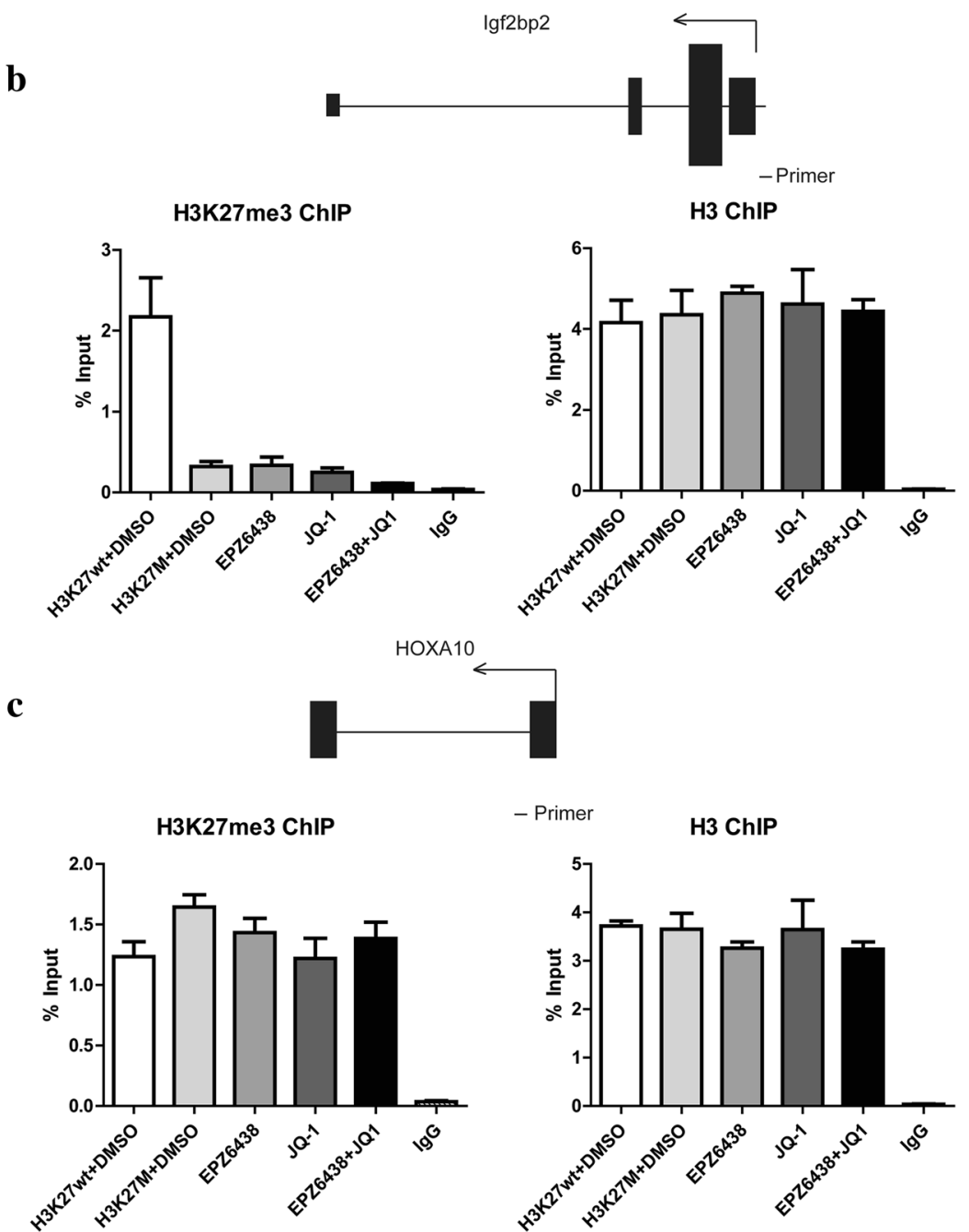

Fig. 5 Combination of EZH2 and BET inhibitors epigenetically regulated tumor-surpressor like p16 $6^{\text {Inka4 }}$. ChIP-q-PCR analysis showing the enrichment of H3K27me3 (left panel) or H3 (right panel) as control over the p16 $6^{\text {Ink4a }}$ gene (a), Igf2bp2 (b) and HOXA10 (c) in the NSCs with different treatment as indicated. The genes and the primer locations were presented on the top of the panel. Data were represented as mean $\pm S D ; n=3$ independent experiments 

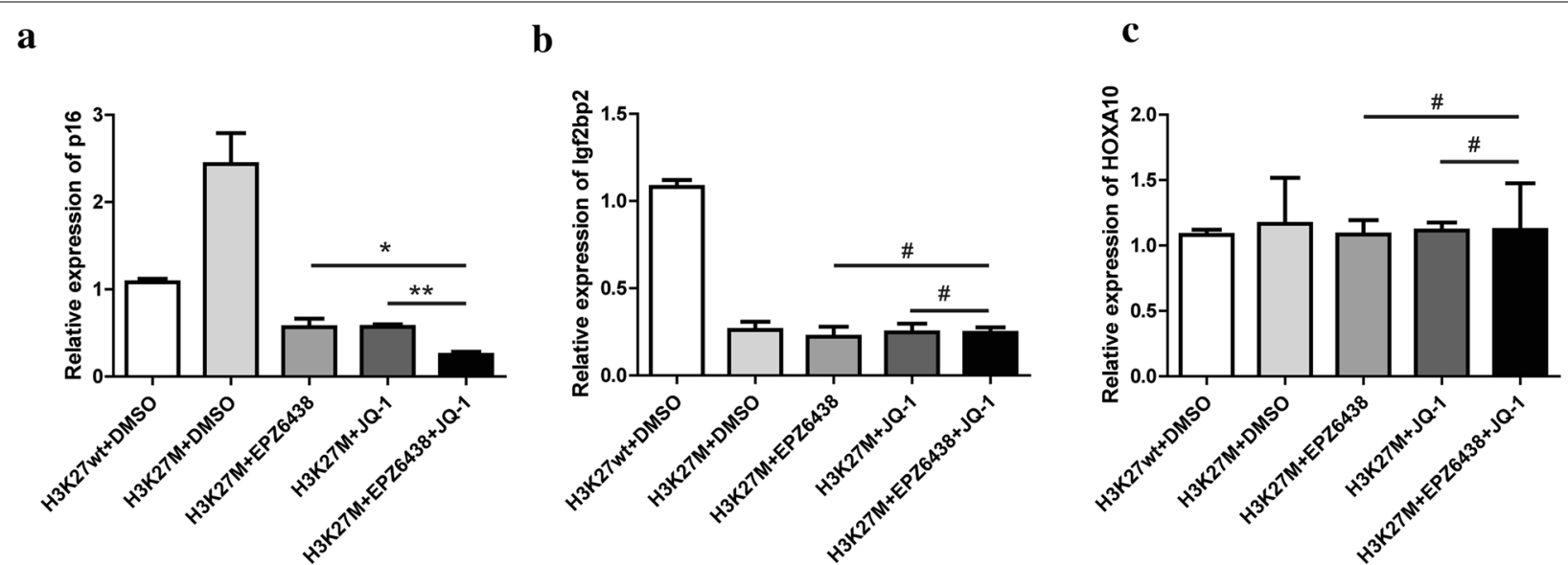

Fig. 6 Gene expression level under the condition of combination of EZH2 and BET inhibitors. Q-PCR analysis showing the mRNA level of p16 (a), Igf2bp2 (b) and HOXA10 (c) gene with the different treatment as indicated. Data were represented as mean \pm SD; $n=3$ independent experiments. ${ }^{*} p<0.05,{ }^{* *} p<0.01$ and ${ }^{\#} p>0.05$

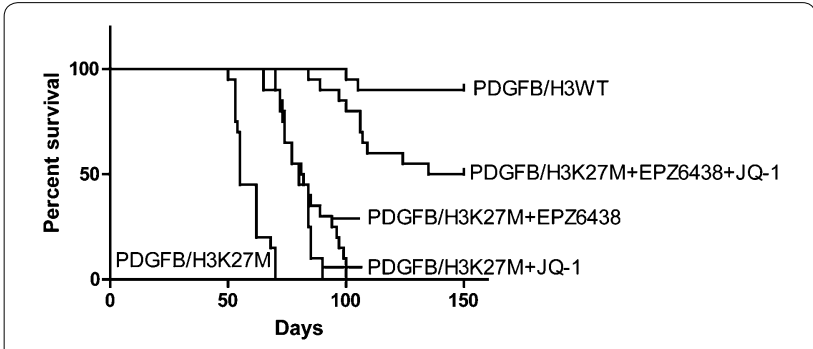

Fig. 7 Combination of EZH2 and BET inhibitors improved survival in mice model. Survival curve of the mice injected into the pons with PDFGB/H3WT or PDGFB/H3K27M NSCs $\left(1 \times 10^{5}\right)$. The inhibitor was given by intraperitoneal (ip) injection with the amount of EPZ6438 by $250 \mathrm{mg} / \mathrm{kg}$ and JQ-1 by $50 \mathrm{mg} / \mathrm{kg}$. Each group has 20 mice

The last type of genes is the PRC2 targets. HOXA10 is a typical PRC2 target, which would retain its H3K27me3 levels even in the presence of H3K27M. This retaining of the H3K27me3 activity would make it keep silencing in the tumor cells. Interestingly, neither of the inhibitors of EZH2 and BET works on this type of genes. The results from SF8628 human DIPG cells revealed a genomewide distribution of $\mathrm{H} 3.3 \mathrm{~K} 27 \mathrm{M}$ that is highly correlated with active transcription, which were acetylated H3K27 (H3K27ac) and RNA polymerase II (RNA pol II) [29]. However, further study showed that H3K27M colocalizes with transcriptionally active chromatin regions were largely excluded from regions that are occupied by PRC2 and H3K27me3. In this case, PRC2 is almost entirely confined to chromatin regions marked with H3K27me3, and this mark is mutually exclusive with H3K27ac. If we compare the overlap between H3K27M and H3K27ac binding regions, it looks like H3K27M occupies many chromatin regions which EZH2 or PRC2 is unlikely [30]. That is the differences between the different loci in our Fig. 5 and maybe the reasons why cells transfected by H3K27M would be sensitive to EPZ6438 and JQ-1 in the loci like Fig. 5a. Thus, we demonstrated combination of EPZ6438 and JQ-1 would affected on the tumor suppressors which is abnormally repressed by H3K27M.

At last, we performed our results on the animal model, the mice transplanted with PDGFB/H3K27M NSCs were treated with EPZ6438 and/or JQ-1. Consistent with the in vitro data, the treatment of the inhibitors proved the survival of the mice and the combination showed the best effect. We realized it is better to generate DIPG xenograft model by primary human DIPG cell lines such as DIPG007, DIPG012, SF7761, SF8628, DIPG017 or DIPG018, unfortunately, we don't have the way to get these cell lines. We also try to generate the cell lines for the human DIPG, but the specimen is limited to us. The xenograft model may provide the further information on the combination effect of these two inhibitors.

\section{Conclusions}

In conclusion, in this study, we used combination of two inhibitors, one response on the inhibition of EZH2, another is for BET proteins. The combination of two inhibitors showed the better effect on the treatment of H3K27M DIPG cells by inhibiting the cell proliferation and promoting the apoptosis through epigenetic regulation of several tumor suppressor genes. These may provide EZH2 and BET proteins as the combined clinical therapy target for DIPG. 


\section{Abbreviations}

DIPG: diffuse intrinsic pontine glioma; PRCs: polycomb repressive complexes; NSCs: neural stem cells.

\section{Authors' contributions}

Did experiments and analyzed the data: YZ,WD, JZ, LW; design the study and draft the manuscript: XW, HS. All authors read and approved the final manuscript.

\section{Author details}

1 Department of Radiology, The 5th Affiliated Hospital of Sun Yat-sen University, No. 52 Meihua Dong Road, Zhuhai 519000, Guangdong Province, People's Republic of China. ${ }^{2}$ Neurosurgery Department, The 1st Affiliated Hospital of Sun Yat-sen University, No. 58 Zhongshan No. 2 Road, Guangzhou 510030, Guangdong Province, People's Republic of China. ${ }^{3}$ Department of Radiology, The 3rd Affiliated Hospital of Sun Yat-sen University, No. 600 Tianhe Road, Guangzhou 510630, Guangdong Province, People's Republic of China. ${ }^{4}$ Department of Interventional Medicine, The 5th Affiliated Hospital of Sun Yat-sen University, No. 52 Meihua Dong Road, Zhuhai 519000, Guangdong Province, People's Republic of China.

\section{Acknowledgements}

None.

\section{Competing interests}

The authors declare that they have no competing interests.

\section{Availability of data and materials}

All data generated or analyzed during this study are included in this published article.

\section{Consent for publication}

All participants have given consent for publication.

\section{Ethics approval and consent to participate}

All protocols, described below, were approved by the Animal Care and Use Committee of Sun Yat-sen University.

\section{Funding}

This project was supported by Science and Technology Program of Zhuhai City, 20171009E30011; National Natural Science Foundation of China (NSFC), 81620108017.

\section{Publisher's Note}

Springer Nature remains neutral with regard to jurisdictional claims in published maps and institutional affiliations.

Received: 1 August 2017 Accepted: 20 October 2017

Published online: 30 October 2017

\section{References}

1. Hargrave D, Bartels U, Bouffet E. Diffuse brainstem glioma in children: critical review of clinical trials. Lancet Oncol. 2006;7:241-8.

2. Puget $S$, Philippe $C$, Bax DA, Job B, Varlet $P$, Junier MP, Andreiuolo F, Carvalho D, Reis R, Guerrini-Rousseau L, et al. Mesenchymal transition and PDGFRA amplification/mutation are key distinct oncogenic events in pediatric diffuse intrinsic pontine gliomas. PLoS ONE. 2012;7:e30313.

3. Donaldson SS, Laningham F, Fisher PG. Advances toward an understanding of brainstem gliomas. J Clin Oncol. 2006;24:1266-72.

4. Schwartzentruber J, Korshunov A, Liu XY, Jones DT, Pfaff E, Jacob K, Sturm D, Fontebasso AM, Quang DA, Tonjes M, et al. Driver mutations in histone $\mathrm{H} 3.3$ and chromatin remodelling genes in paediatric glioblastoma. Nature. 2012;482:226-31.

5. Wu G, Broniscer A, McEachron TA, Lu C, Paugh BS, Becksfort J, Qu C, Ding $L$, Huether R, Parker M, et al. Somatic histone $H 3$ alterations in pediatric diffuse intrinsic pontine gliomas and non-brainstem glioblastomas. Nat Genet. 2012;44:251-3.
6. Buczkowicz P, Hoeman C, Rakopoulos P, Pajovic S, Letourneau L, Dzamba M, Morrison A, Lewis P, Bouffet E, Bartels U, et al. Genomic analysis of diffuse intrinsic pontine gliomas identifies three molecular subgroups and recurrent activating ACVR1 mutations. Nat Genet. 2014;46:451-6.

7. Taylor KR, Mackay A, Truffaux N, Butterfield YS, Morozova O, Philippe C, Castel D, Grasso CS, Vinci M, Carvalho D, et al. Recurrent activating ACVR1 mutations in diffuse intrinsic pontine glioma. Nat Genet. 2014;46:457-61.

8. Fontebasso AM, Papillon-Cavanagh S, Schwartzentruber J, Nikbakht H, Gerges N, Fiset PO, Bechet D, Faury D, De Jay N, Ramkissoon LA, et al. Recurrent somatic mutations in ACVR1 in pediatric midline high-grade astrocytoma. Nat Genet. 2014;46:462-6.

9. Lewis PW, Muller MM, Koletsky MS, Cordero F, Lin S, Banaszynski LA, Garcia BA, Muir TW, Becher OJ, Allis CD. Inhibition of PRC2 activity by a gain-of-function $\mathrm{H} 3$ mutation found in pediatric glioblastoma. Science. 2013;340:857-61.

10. Herz HM, Morgan M, Gao X, Jackson J, Rickels R, Swanson SK, Florens L, Washburn MP, Eissenberg JC, Shilatifard A. Histone H3 lysine-to-methionine mutants as a paradigm to study chromatin signaling. Science. 2014;345:1065-70.

11. Lewis EB. A gene complex controlling segmentation in Drosophila. Nature. 1978:276:565-70.

12. Margueron R, Reinberg D. The polycomb complex PRC2 and its mark in life. Nature. 2011;469:343-9.

13. Christofides A, Karantanos T, Bardhan K, Boussiotis VA. Epigenetic regulation of cancer biology and anti-tumor immunity by EZH2. Oncotarget. 2016;7:85624-40.

14. Orkin SH, Hochedlinger K. Chromatin connections to pluripotency and cellular reprogramming. Cell. 2011;145:835-50.

15. Kim KH, Roberts CW. Targeting EZH2 in cancer. Nat Med. 2016;22:128-34.

16. Mohammad F, Weissmann S, Leblanc B, Pandey DP, Hojfeldt JW, Comet I, Zheng C, Johansen JV, Rapin N, Porse BT, et al. EZH2 is a potential therapeutic target for H3K27M-mutant pediatric gliomas. Nat Med. 2017;23:483-92.

17. Zeng L, Zhou MM. Bromodomain: an acetyl-lysine binding domain. FEBS Lett. 2002;513:124-8.

18. Dhalluin C, Carlson JE, Zeng L, He C, Aggarwal AK, Zhou MM. Structure and ligand of a histone acetyltransferase bromodomain. Nature. 1999:399:491-6.

19. Marushige K. Activation of chromatin by acetylation of histone side chains. Proc Natl Acad Sci USA. 1976;73:3937-41.

20. Delmore JE, Issa GC, Lemieux ME, Rahl PB, Shi J, Jacobs HM, Kastritis E, Gilpatrick T, Paranal RM, Qi J, et al. BET bromodomain inhibition as a therapeutic strategy to target c-Myc. Cell. 2011;146:904-17.

21. Dey A, Nishiyama A, Karpova T, McNally J, Ozato K. Brd4 marks select genes on mitotic chromatin and directs postmitotic transcription. Mol Biol Cell. 2009;20:4899-909.

22. Rahl PB, Lin CY, Seila AC, Flynn RA, McCuine S, Burge CB, Sharp $P A$, Young RA. C-Myc regulates transcriptional pause release. Cell. 2010;141:432-45.

23. Yang Z, He N, Zhou Q. Brd4 recruits P-TEFb to chromosomes at late mitosis to promote $\mathrm{G} 1$ gene expression and cell cycle progression. Mol Cell Biol. 2008;28:967-76.

24. Muller S, Filippakopoulos P, Knapp S. Bromodomains as therapeutic targets. Expert Rev Mol Med. 2011;13:e29.

25. Barbieri I, Cannizzaro E, Dawson MA. Bromodomains as therapeutic targets in cancer. Brief Funct Genom. 2013;12:219-30.

26. Sturm D, Witt H, Hovestadt V, Khuong-Quang DA, Jones DT, Konermann C, Pfaff E, Tonjes M, Sill M, Bender S, et al. Hotspot mutations in H3F3A and $\mathrm{IDH} 1$ define distinct epigenetic and biological subgroups of glioblastoma. Cancer Cell. 2012;22:425-37.

27. Bender $S$, Tang $Y$, Lindroth AM, Hovestadt $V$, Jones DT, Kool M, Zapatka M, Northcott PA, Sturm D, Wang W, et al. Reduced H3K27me3 and DNA hypomethylation are major drivers of gene expression in K27M mutant pediatric high-grade gliomas. Cancer Cell. 2013;24:660-72.

28. Chan KM, Fang D, Gan H, Hashizume R, Yu C, Schroeder M, Gupta N, Mueller S, James CD, Jenkins $\mathrm{R}$, et al. The histone H3.3K27M mutation in pediatric glioma reprograms H3K27 methylation and gene expression. Genes Dev. 2013;27:985-90. 
29. Piunti A, Hashizume R, Morgan MA, Bartom ET, Horbinski CM, Marshall SA, Rendleman EJ, Ma Q, Takahashi YH, Woodfin AR, et al. Therapeutic targeting of polycomb and BET bromodomain proteins in diffuse intrinsic pontine gliomas. Nat Med. 2017;23:493-500.
30. Weiner A, Lara-Astiaso D, Krupalnik V, Gafni O, David E, Winter DR, Hanna JH, Amit I. Co-ChIP enables genome-wide mapping of histone mark co-occurrence at single-molecule resolution. Nat Biotechnol. 2016;34:953-61.

\section{Submit your next manuscript to BioMed Central} and we will help you at every step:

- We accept pre-submission inquiries

- Our selector tool helps you to find the most relevant journal

- We provide round the clock customer support

- Convenient online submission

- Thorough peer review

- Inclusion in PubMed and all major indexing services

- Maximum visibility for your research

Submit your manuscript at

www.biomedcentral.com/submit 